\title{
O efeito da exodontia dos primeiros pré-molares sobre a AFAl*
}

Flávio Marcos de ALMEIDA**, Vania Célia Vieira de SIQUEIRA***

\begin{abstract}
Resumo
A extração dos pré-molares ocorre convencionalmente como parte da terapia ortodôntica, no intuito de resolver uma série de problemas. Todavia sua utilização para o controle da dimensão vertical gera muitas controvérsias. Esse estudo retrospectivo avaliou cefalometricamente as telerradiografias, tomadas em norma lateral, de 30 jovens do gênero feminino, com má oclusão do tipo Classe II, divisão 1, dolicofaciais, com idade média de 12,3 anos, variando entre 9 e 17 anos, tratadas ortodonticamente com aparelho fixo tipo edgewise e uso de extrabucal com tração alta, das quais 15 submeteram-se à exodontia dos primeiros pré-molares e as outras 15 não realizaram exodontias. As medidas cefalométricas N-Me, N-ENA, ENA-Me, S-Go, Ar-Go, 6-PP, 6-ENAperp, 6-GoGn, 6-Pogperp, SN.GoGn, SN.PP, PP.GoGn, ENA-Me/N-Me, S-Go/N-Me e Go-Ar/S-Go foram estudadas. Os resultados revelaram: 1) que a exodontia dos primeiros pré-molares, associada à extrusão dos primeiros molares e ao crescimento, não permitiu uma diferença nas alterações da AFAI entre os grupos, 2) ocorreu uma mesialização dos molares superiores e inferiores no grupo com exodontias, 3) a AFAT aumentou similarmente nos dois grupos, 4) o aumento da AFAT ocorreu de forma significativamente maior no grupo sem exodontias, devido ao maior aumento da AFAS, indicando que o crescimento possui um papel preponderante no controle da dimensão vertical durante o tratamento ortodôntico, 5) observamos a manutenção dos valores angulares durante o tratamento devido principalmente ao crescimento vertical posterior que ocorreu na mesma proporção do crescimento da região anterior da face em ambos os grupos durante o tratamento ortodôntico.
\end{abstract}

Palavras-chave: Altura facial ântero-inferior. Exodontia. Pré-molares.

\section{INTRODUÇÃO}

A realização de exodontias dentárias como parte da terapia ortodôntica ocorre convencionalmente, mas ainda provoca muitas controvérsias. Desde o início da especialidade ortodôntica, os profissionais reconheceram a influência do tratamento sobre o perfil facial, entretanto, não existia uma concordância em relação ao tipo de tratamento ortodôntico mais apropriado.

Angle preconizava que somente com a ma-

* Resumo da Dissertação de Mestrado apresentada ao curso de pós-graduação em Ortodontia da Pontifícia Universidade Católica de Minas Gerais PUC/Minas.

** Mestre em Ortodontia pela Pontifícia Universidade Católica de Minas Gerais PUC/Minas

*** Professora Assistente Doutora da disciplina de Ortodontia da Faculdade de Odontologia de Piracicaba UNICAMP. Professora Adjunta III da disciplina de Ortodontia da Pontifícia Universidade Católica de Minas Gerais PUC Minas. Orientadora da dissertação de mestrado. 
nutenção de todos os dentes no arco seria possível obter o perfil facial ideal. Case e seus seguidores se opunham a essa idéia e afirmavam que, em alguns tratamentos, existia a necessidade da realização de exodontias para se obter um bom resultado, recomendando-as em cerca de $10 \%$ dos $\operatorname{casos}^{17}$.

Atualmente a literatura possui relatos de efeitos favoráveis e desfavoráveis, decorrentes das extrações, para o perfil facial e para o posicionamento dentário. Indica-se a extração de pré-molares durante um tratamento ortodôntico para o alívio do apinhamento, para a retração dos dentes anteriores e para corrigir as relações dentárias ânteroposteriores com perdas de ancoragem diferenciadas nos arcos maxilar e mandibular $4,5,6,7,8$.

De acordo com alguns autores os movimentos horizontais e verticais dos molares produzem alterações, influenciando favorável ou desfavoravelmente a dimensão vertical dos pacientes ${ }^{32,36,37,45}$. Assim, a exodontia dos pré-molares com o objetivo de diminuir a altura facial ântero-inferior (AFAI) ainda é objeto de questionamento. Muitos a recomendam em pacientes dolicofaciais, ou seja, com altura facial ânterior e ângulo do plano mandibular aumentados, a fim de obter um movimento mesial dos molares com uma conseqüente rotação anterior da mandíbula e diminuição da altura facial ântero-inferior ${ }^{30,36,37,58,59,60}$, enquanto outros $^{1,12,15,27,48}$ não relatam tal diminuição, e, pelo contrário, em alguns casos, constataram até mesmo um leve aumento.

Observamos que os autores não são unânimes em suas conclusões. O movimento ântero-posterior e vertical dos molares em jovens submetidos a tratamentos ortodônticos com e sem exodontias, o crescimento e o padrão facial são fatores que podem influenciar favorável ou desfavoravelmente nos resultados de um tratamento ortodôntico, em relação às alterações verticais. Portanto, torna-se necessário reavaliar esses parâmetros e verificar se eles realmente influenciam o resultado final.

\section{REVISÃO DA LITERATURA}

Aspectos relativos ao crescimento craniofacial

Schudy ${ }^{45}$ observou longitudinalmente 270 jovens, de ambos os gêneros, dos 11 aos 14 anos de idade, sem tratamento ortodôntico, com o objetivo de avaliar os efeitos das proporções faciais sobre a sobremordida e a função. Concluiu que as variações verticais são mais significantes para a identificação dos tipos faciais, afirmando que os termos retrognatismo e prognatismo são inadequados, introduzindo o termo divergência facial para classificar os pacientes. Sugeriu os termos hipodivergentes e hiperdivergentes como extremos da divergência facial, sendo hiperdivergentes aqueles com o ângulo SN.PM maior que $34^{\circ}$, e os hipodivergentes com este ângulo menor que $31^{\circ}$. Para o autor, a altura facial ântero-inferior é a região da face que sofre as maiores variações com o crescimento e com o tratamento ortodôntico, sendo a maior responsável pelas alterações da proporção entre altura facial anterior total e altura facial ântero-inferior, que é de $56 \%$ nos pacientes equilibrados, $59,5 \%$ nos retrognatas e $54,1 \%$ nos prognatas. $\mathrm{O}$ autor considera as proporções entre a profundidade e altura facial total, e entre a altura facial posterior e altura facial ântero-inferior as mais significantes para a avaliação do tipo facial.

Singh e Savara ${ }^{46}$, preocupados com a falta de dados normativos que informem sobre as dimensões das estruturas que compõem a face média, desenvolveram um estudo longitudinal com 50 jovens, do gênero feminino, a fim de alcançar três objetivos: definir a tendência média de crescimento da maxila em relação à altura, comprimento e largura, obter as médias e a variabilidade anual dos incrementos relativos e absolutos de cada uma dessas medidas e definir o crescimento circumpuberal na maxila. Concluíram que o pico de crescimento maxilar ocorre entre os 10 e 12 anos de idade, é maior na altura, menor no comprimento e menor ainda na largura, e que parte desse crescimento ocorre precocemente na adolescência e então sofre um declínio anual. 
Bjork $^{9}$ estudou longitudinalmente o crescimento craniofacial em telerradiografias, tomadas em norma lateral, em uma amostra de 100 jovens de ambos os gêneros, dos 4 aos 24 anos de idade, que receberam implantes metálicos, como pontos fixos de referência, com o objetivo principal de verificar o crescimento rotacional mandibular e localizar sítios reais de aposição e reabsorção óssea. Identificou dois tipos básicos de rotação mandibular: anterior e posterior, classificadas em subtipos. O autor descreveu o método estrutural, no qual é possível predizer, a partir de uma única telerradiografia, a tendência de crescimentos rotacionais extremos, baseando-se em sete sinais estruturais, a inclinação do côndilo, a curvatura do canal mandibular, a forma da borda inferior da mandíbula, a inclinação da sínfise, o ângulo interincisivos e interpré-molares e a altura facial ântero-inferior. Com os trabalhos desenvolvidos posteriormente por Skiller ${ }^{10,11}$, os princípios descritos sedimentaram-se.

Isaacson et al. ${ }^{23}$ correlacionaram os parâmetros verticais faciais e a rotação mandibular, avaliando 60 telerradiografias, tomadas em norma lateral, sendo 20 com o ângulo SN.PM maior que 32 graus, 20 menor que 26 graus e 20 igual a 32 graus. Todos os jovens realizaram a tomada radiográfica em uma idade média de 13,34 anos no grupo braquifacial; 13,26 anos no mesofacial e 14, 20 anos no dolicofacial. Dentre as conclusões obtidas, os autores relatam que: 1) a curva de Spee dever ser nivelada com cautela em jovens com padrão de crescimento alterado a fim de não estimular a rotação posterior da mandíbula; 2) os elásticos intermaxilares produzem extrusão e são indicados nos jovens braquifaciais e contra indicados nos dolicofaciais; 3) as exodontias de pré-molares são contra indicadas nos casos de mordidas fechadas esqueléticas e indicadas nas mordidas abertas. Finalizam que nos casos com padrão de crescimento equilibrado, pequenos efeitos colaterais indesejáveis ou pequenas falhas na mecanoterapia não comprometem os resulta- dos. Mas naqueles casos com padrão esqueléticos discrepantes, que representam pelo menos um terço dos nossos tratamentos, os mesmos devem ser conduzidos cuidadosamente a fim de não comprometer o resultado final.

Tofani ${ }^{52}$ investigou o crescimento mandibular avaliando longitudinalmente 20 jovens do gênero feminino, dos 9 aos 18 anos de idade, por meio de telerradiografias, tomadas em norma frontal e lateral, e radiografias da mão e punho, três anos antes e três depois da menarca. Concluiu que a mandíbula continua a crescer após a menarca, mas o crescimento mandibular é significativamente maior antes da menarca, nas quatro dimensões avaliadas. O pico de crescimento corporal ocorre antes do pico de crescimento mandibular e que o início da fusão das falanges distais dos dedos apresenta o maior índice de correlação com o pico de crescimento mandibular, tornando-se o melhor parâmetro para predizer o surto de crescimento puberal mandibular.

Dermaut e O'Reilly ${ }^{16}$ avaliaram longitudinalmente as telerradiografias, tomadas em norma lateral, obtidas anualmente, três anos antes e três depois da puberdade, de 24 jovens do gênero feminino, leucodermas, com relação ântero-posterior e vertical normais e sem tratamento ortodôntico prévio. Dentre as conclusões observadas verificaram que existiu uma extrema variabilidade na quantidade e na época do crescimento das medidas cefalométricas estudadas, que o pico da velocidade de crescimento da altura facial ânterosuperior ocorreu mais freqüentemente nas idades de 11 e 12 anos, e da altura facial ântero-inferior e total nas idades de 12 e 13 anos, e que a maior parte do crescimento vertical anterior ocorreu antes da menarca, na maioria dos casos.

$\mathrm{Nanda}^{33}$ avaliou o padrão de crescimento facial em jovens com mordidas abertas e fechadas esqueléticas com o objetivo de verificar em qual época do desenvolvimento pós-natal é possível reconhecer o estabelecimento dessas anormalidades oclusais e, uma vez identificada, verificar se 
a tendência persiste durante o desenvolvimento. Dados longitudinais obtidos de telerradiografias anuais, tomadas em norma lateral, de 16 jovens do gênero masculino e 16 do feminino, dos 3 aos 18 anos de idade, definiram a amostra. A seleção desses jovens baseou-se na proporção entre a altura facial anterior total (N-Me) e a altura facial ântero-inferior (ENA-Me). Dezesseis jovens com mordida fechada esquelética e 16 com mordida aberta esquelética foram subdivididos em quatro grupos de oito, por gênero. Os jovens com mordida fechada esquelética demonstraram um maior crescimento da altura facial ântero-superior, enquanto que nos jovens com mordida aberta ocorreu um maior crescimento da altura facial ântero-inferior. O desenvolvimento da dimensão posterior da face não apresentou diferenças entre os grupos, o padrão de desenvolvimento de cada tipo facial definiu-se muito cedo, mesmo antes da erupção dos primeiros molares permanentes, sendo o padrão de mordida aberta nas jovens do gênero feminino o primeiro a ser definido, seguido de jovens do gênero feminino com mordida fechada, masculino com mordida aberta e masculino com mordida fechada. Para o autor, esses achados possuem uma relevância clínica, auxiliando na determinação da época do tratamento ortodôntico, no tempo de contenção e na previsão da relação oclusal do adulto a partir da dentição mista.

Rothstein e Yoon-Tarlie ${ }^{42}$ descreveram e analisaram as características esqueléticas, dentofaciais e craniofaciais associadas à má oclusão do tipo Classe II, divisão 1, com o objetivo de determinar se essa má oclusão caracteriza-se por um subdesenvolvimento ou um posicionamento posterior mandibular. Duzentas e setenta e oito (268) telerradiografias, tomadas em norma lateral, formaram o grupo de jovens com oclusão equilibrada e 335 o grupo com má oclusão do tipo Classe II, divisão 1, de ambos os gêneros, com idades de 10, 12 e 14 anos. Os autores concluíram que tanto a mandíbula quanto a dentadura no grupo da Classe II apresentaram-se similares às dos grupos controle em relação ao tamanho, forma e posição, exceto pela altura da sínfise, a qual é maior no gênero masculino no grupo da Classe II, que os molares superiores se posicionam mesialmente na Classe II quando comparados ao grupo controle, que o segmento anterior maxilar é mais protrusivo e posicionado mais superiormente na má oclusão de Classe II, que o comprimento excessivo da porção anterior da base do crânio pode ser um fator etiológico da Classe II.

\section{Aspectos relativos ao tratamento ortodôntico}

Merrifield e $\mathrm{Cross}^{32}$ afirmaram que tanto o movimento horizontal quanto o vertical dos molares influenciam a dimensão vertical dos pacientes, citando que nos tratamentos de Classe II sem exodontia, com distalização dos molares superiores, ocorre um aumento de $1,3 \mathrm{~mm}$ na altura facial anterior para cada $1 \mathrm{~mm}$ de distalização, e que o movimento extrusivo do molar superior provocado pelo uso do extrabucal cervical ou qualquer outra mecânica extrusiva produz uma rotação pósteroinferior da mandíbula. Cada milímetro de extrusão do molar superior promove $0,75^{\circ}$ de abertura do ângulo FMA, $0,5^{\circ}$ de aumento do ângulo ANB e $0,5 \mathrm{~mm}$ de deslocamento posterior do molar inferior. Para esses autores, se uma direção de força apropriada não for usada, o vetor resultante pode ser para baixo e para trás, aumentando o FMA, inclinando o plano oclusal, conseqüentemente promovendo um posicionamento mais inferior e posterior do ponto $\mathrm{B}$, causando um aumento da altura facial, incisivos inferiores retro-inclinados e um sorriso gengival aumentado.

Pearson ${ }^{36}$, avaliando a importância do controle vertical nos pacientes com tendência de crescimento rotacional posterior, afirmou que a extração dos pré-molares, associado ao uso de uma mentoneira de tração vertical, permite uma mesialização dos dentes posteriores com conseqüente fechamento do plano mandibular. $\mathrm{O}$ autor relatou o tratamento de 20 jovens em crescimento, 11 do gênero feminino e 9 do masculino, com idade média de 11 , 
5 anos, todos com o ângulo do plano mandibular variando entre $37^{\circ}$ e $48^{\circ}$, nos quais foram realizadas extrações dos primeiros pré-molares e uso de mentoneira vertical, 12 horas por dia, com uma força mínima de 500 gramas. Obteve um fechamento do plano mandibular de $3,9^{\circ}$ em média, conseqüentemente auxiliando na redução de todas as mordidas abertas. $\mathrm{O}$ autor relatou que nos casos de adultos que apresentaram um crescimento vertical excessivo, a extração dos pré-molares superiores e o uso de extrabucal com tração alta beneficiaram o controle vertical.

Baumrind et al. ${ }^{3}$ avaliaram quais alterações cefalométricas durante um tratamento ortodôntico apresentavam maior índice de correlação com as alterações do ângulo do plano mandibular. A alteração com o maior índice de correlação foi o movimento horizontal do primeiro molar superior, pois a quantidade de distalização foi diretamente proporcional à abertura do ângulo do plano mandibular. A segunda correlação importante foi o movimento vertical dos molares. Os autores constataram que o movimento horizontal se mostra duas vezes mais importante que o vertical na posição final da mandíbula. Dessa forma, a alteração desse plano será influenciada pela quantidade de distalização e extrusão dos molares superiores para a correção da Classe II, nos casos sem exodontia de pré-molares.

Teuscher ${ }^{51}$ simulou graficamente os prováveis resultados ortodônticos e ortopédicos de diferentes tipos de tração extrabucal aplicados nos dentes superiores. Para o autor, a força e os movimentos são vetores, e uma reação a uma força aplicada sobre um tecido duro qualquer depende principalmente da posição do seu centro de resistência, da quantidade e do tempo de força aplicada. Nos jovens em crescimento, o movimento resultante será obtido pela adição dos vetores da força aplicada e do vetor de crescimento. Quando um aparelho extrabucal cervical é utilizado, o resultado da simulação sugere que, ao se levantar o arco externo, obtêm-se um menor efeito de distalização, diminuição do controle vertical, e uma tendência maior de abrir a mor- dida. Por outro lado, quando se aplica uma força extrabucal de tração alta, a simulação gráfica indica que a mudança da aplicação da força, sem alterar a angulação do braço externo, produz uma alteração na rotação do molar de horária para anti-horária e, conseqüentemente, uma perda do controle vertical dos molares e dos incisivos.

Staggers ${ }^{48}$ observou que, após a exodontia dos pré-molares, o molar superior sofreu um movimento ântero-inferior de 4,8mm, o molar inferior apresentou um movimento ântero-superior de $3,7 \mathrm{~mm}$, enquanto o ângulo PM.PH diminuiu apenas $0,5^{\circ}$. Esses dados indicaram que mesmo com a movimentação anterior dos molares, a extrusão impediu qualquer perda significante da dimensão vertical.

Tulloch, Medland e Tuncay ${ }^{53}$ e Tunkay e Tullo$\mathrm{ch}^{54}$ avaliaram de forma sistemática 50 artigos referentes a tratamentos de jovens com má oclusão do tipo Classe II, publicados entre os anos de 1980 a 1987, com o objetivo de determinar se os aparelhos ortodônticos podem realmente influenciar o crescimento desses pacientes ou se existe necessidade de maiores investigações. As variáveis consideradas para avaliar os estudos incluíam os aparelhos utilizados, a seleção de pacientes, os métodos de comparação dos grupos, o projeto da pesquisa e a forma de obtenção, análise e discussão dos resultados. Os autores observaram que poucos estudos reportaram claramente os critérios de seleção dos seus pacientes, os fatores que influenciaram a interrupção ou a mudança de alguns tratamentos, e se ocorreram desistências de pacientes durante o período da pesquisa. Os testes estatísticos utilizados nem sempre eram os mais indicados, e os dados referentes à idade, ao gênero, à maturação e à duração do tratamento eram citados mas raramente ajustados para a utilização nas análises. Devido às diversas técnicas de tratamentos ortodônticos empregados, amostras geralmente pequenas, projetos de pesquisa pouco embasados e dados importantes reportados de forma incompleta, não se pode concluir ainda se o tratamento ortodôntico influencia o crescimento em pacientes com Classe II. 
Harris, Dyer e Vaden ${ }^{18,20}$ realizaram dois trabathos comparando as diferenças entre os resultados de tratamentos ortodônticos realizados em 26 adultos com idade média de 27,6 anos e 30 adolescentes com a idade média de 12,5 anos, todas do gênero feminino, com exodontia de quatro pré-molares tratadas com mecânica de Tweed associado ao extrabucal de tração alta ou reta e a elásticos intermaxilares. Concluíram que o crescimento mandibular nas adolescentes contribuiu em $70 \%$ para a correção da relação molar e o movimento ortodôntico em $30 \%$, enquanto, nas adultas, o movimento dentário foi o responsável pela correção da relação oclusal dos molares. Observaram que no grupo adulto, concomitante com a extrusão dos molares inferiores, ocorreu uma intrusão dos molares superiores que ajudou a minimizar qualquer mudança esquelética vertical, mesmo com a inclinação do plano oclusal, ocorrida devido aos elásticos intermaxilares.

Klapper et al. ${ }^{26}$ avaliaram a influência do tratamento ortodôntico utilizando extração e não extração dos primeiros pré-molares sobre o padrão de crescimento de jovens braquifaciais e dolicofaciais, e afirmaram que a extração dos pré-molares nos dolicofaciais deve ser considerada para controle vertical, pois existe uma forte tendência de abertura do eixo facial em ambos os tipos faciais, quando o molar superior é distalizado entre 3 e $5 \mathrm{~mm}$, nos pacientes com má oclusão do tipo Classe II tratados sem exodontia.

Proffiti, Phillips e Douvartzidis ${ }^{38}$, por meio de um estudo retrospectivo, compararam os resultados do tratamento ortodôntico utilizando exodontia de pré-molares, com tratamento ortocirúrgico em pacientes com Classe II esquelética, sem crescimento. No grupo do tratamento ortodôntico, os autores avaliaram 22 do gênero feminino e 11 do masculino, e no grupo cirúrgico 42 do gênero feminino e 15 do masculino. Observaram que, no grupo com exodontia dos quatro pré-molares, o ponto A moveu-se inferiormente $0,9 \mathrm{~mm}$ em média, que o ponto B movimentouse em média $1 \mathrm{~mm}$ inferiormente e que o plano mandibular aumentou $0,27^{\circ}$.

Chua, Lim e Lubit ${ }^{12}$ examinaram o efeito do tratamento ortodôntico com e sem exodontia dos quatro primeiros pré-molares sobre a altura facial ântero-inferior (AFAI) em 174 jovens em crescimento. Os resultados obtidos mostraram que tratamentos ortodônticos sem exodontias associam-se a uma rotação inferior e posterior da mandíbula com conseqüente aumento da AFAI, enquanto os tratamentos com exodontia não relacionam-se com qualquer alteração da altura facial ântero-inferior.

Cusimano, McLaughlin e Zernik ${ }^{15}$ investigaram as mudanças no ângulo do plano mandibular em jovens dolicofaciais, com idade média de 11 anos ao início do tratamento, tratados com extração dos quatro primeiros pré-molares e mesialização dos dentes posteriores. Observaram a mesialização dos molares superiores e inferiores associada ao movimento de extrusão, mas não constataram alterações significantes do ângulo do plano mandibular que alterou de $39,4^{\circ}$ do início para $39,8^{\circ}$ ao final do tratamento. Concluíram que o movimento vertical dos molares, associado ao crescimento vertical das estruturas craniofaciais, impediu a diminuição do ângulo do plano mandibular que poderia ocorrer devido ao movimento mesial dos mesmos, mantendo-o praticamente inalterado.

Staggers ${ }^{49}$ comparou 38 jovens tratados com extração dos quatro primeiros pré-molares com 45 sem extração, com o objetivo de avaliar as alterações faciais verticais ocorridas. $\mathrm{O}$ autor não observou uma diminuição da dimensão vertical nos pacientes submetidos à extração. Ao contrário, observou um leve aumento em ambos os grupos sem diferenças significantes entre eles. Concluiu que os dados deste estudo não suportam a teoria de que extração dos primeiros pré-molares reduz a dimensão vertical.

Para Ortial ${ }^{34}$, o controle da dimensão vertical possui um papel preponderante em um tratamento ortodôntico. Em uma amostra de 323 jovens, ele observou um padrão mesofacial em $51 \%$, uma mordida profunda esquelética em $26 \%$ e uma mordida aberta esquelética em 23\%, baseando-se no 
ângulo FMA. A partir dessa classificação, descreveu casos clínicos considerados representativos de cada grupo, todos tratados com mecânica de força direcional de Tweed-Merrifield ${ }^{32}$, com diferentes padrões de extração. A adolescente representante do grupo mesofacial tratou com exodontia dos primeiros pré-molares superiores e segundos inferiores, obtendo-se uma redução do FMA de $26^{\circ}$ para $17^{\circ}$. A representante do grupo de mordida aberta esquelética iniciou o tratamento com um ângulo de $40^{\circ}$ e após o tratamento com exodontias de quatro pré-molares e primeiros molares, obteve uma redução de $5^{\circ}$ do FMA. O autor concluiu que o controle da dimensão vertical é importante principalmente nos casos com extração, com o objetivo principal de obter um equilíbrio facial, além de melhorar a oclusão.

Karlsen ${ }^{25}$ estudou longitudinalmente as telerradiografias, tomadas em norma lateral, de dois grupos de 29 jovens, classificados de acordo com o ângulo SN-PM, considerado baixo quando encontrava-se em torno de $26^{\circ}$ ou em um valor menor e alto quando próximo a $35^{\circ}$ ou maior, de ambos os gêneros, aos 6, 12, 15 de idade, sem necessidade de tratamento ortodôntico. Avaliou as associações entre o crescimento dimensional da face e o deslocamento rotacional da mandíbula no período juvenil e durante a puberdade. As medidas rotacionais mandibulares basearam-se nos trabalhos de Bjork e Skieller ${ }^{11}$. Observou que o desenvolvimento excessivo da AFAI, nos casos de mordida aberta esquelética, ocorreu principalmente devido ao ângulo do plano mandibular aumentado que direcionou o crescimento do corpo mandibular mais para baixo do que o normal e não por causa de uma rotação inferior mandibular.

Sarisoy e Darendeliler ${ }^{43}$ avaliaram o efeito de diferentes padrões de crescimento e de tipos de tratamento sobre as estruturas craniofaciais em pacientes tratados com ortodontia corretiva e exodontia de pré-molares. $\mathrm{O}$ tratamento diferenciou-se em relação ao uso ou não de aparelhos extrabucais e em relação ao padrão de crescimento, e os jovens foram divididos em mesiodivergentes e hiperdivergentes. Observaram que o aumento da altura facial ocorreu de forma significantemente diferente entre os grupos mesiodivergentes e hiperdivergentes, e que a extração dos pré-molares e o uso de extrabucal não alteraram esse padrão de crescimento. Concluíram que o padrão de crescimento é que primariamente determina as respostas das estruturas craniofaciais em tratamentos ortodônticos com extração.

Com o objetivo de avaliar as mudanças verticais ocorridas em jovens tratados ortodonticamente com e sem exodontia dos primeiros pré-molares, Kocadereli ${ }^{27}$ selecionou 40 jovens, tratados sem exodontia e 40 com exodontia dos primeiros pré-molares. Todos apresentavam má oclusão do tipo Classe I, utilizaram aparelho fixo do tipo edgewise, sem o emprego do aparelho extrabucal. $\mathrm{O}$ autor concluiu que a extração dos primeiros pré-molares não provoca diminuição da dimensão vertical do paciente e não deve ser usada como auxiliar nos tratamentos que necessitam diminuir a altura facial ântero-inferior.

Apolinário e Jardim ${ }^{1}$ avaliaram as alterações verticais da mandíbula ocorridas após a exodontia dos quatro primeiros pré-molares em pacientes considerados sem crescimento, a fim de verificarem se esse tipo de tratamento promoveria o fechamento do ângulo entre as bases maxilar e mandibular. Utilizaram uma amostra composta de 25 pacientes com má oclusão do tipo Classe I, tratados com aparelhos fixos e exodontia dos quatro primeiros pré-molares, avaliados por meio de telerradiografias, tomadas em norma lateral, antes e após o tratamento de cada um deles. Concluíram que não ocorreu alteração significativa entre as medidas verticais analisadas, a saber: ângulo basal, formado entre o plano palatino ENA-ENP e o plano mandibular Go-Me; e a razão AFI/AFT X100, medida proporcional onde a altura facial total AFT é representada pela distância $\mathrm{N}$ até $\mathrm{Me}$ e a altura facial inferior, AFI é representada pela distância entre o Mento e uma linha perpendicular a N-Me passando por ENA. 


\section{PROPOSIÇÃO}

O presente trabalho avaliou o efeito das exodontias dos quatro primeiros pré-molares, sobre a AFAI em pacientes do gênero feminino, leucodermas, dolicofaciais, em crescimento, com má oclusão do tipo Classe II, divisão 1 , que se submeteram a tratamento ortodôntico corretivo e uso de aparelho extrabucal e compará-las com um grupo de jovens com as mesmas características descritas acima, mas que se submeteram ao tratamento ortodôntico sem extrações. Os dados sobre as alterações da altura facial foram avaliados ao início ao final do tratamento.

\section{MATERIAL E MÉTODOS Material}

Do acervo de documentações ortodônticas pertencentes à Disciplina de pós-graduação em Ortodontia da Faculdade de Odontologia da PUC/Minas, analisaram-se as telerradiografias, tomadas em norma lateral, de 648 jovens que se submeteram a tratamento ortodôntico corretivo, na referida disciplina. Elegeram-se trinta jovens, leucodermas, do gênero feminino, que apresentavam inicialmente má oclusão do tipo Classe II, divisão 1, com padrão vertical de crescimento determinado pelo ângulo SN.GoGn maior ou igual a $32^{\circ}$, segundo os preceitos de Steiner ${ }^{50}$, sendo quinze tratadas com extrações dos quatro primeiros pré-molares, com idade média de 142,5 meses (aproximadamente 11 anos e 10 meses) variando entre 109 e 196 meses, caracterizando o grupo experimental (C), e quinze sem extrações, com idade média de 153,3 meses (aproximadamente 12 anos e 9 meses) variando entre 108 e 205 meses, caracterizando o grupo controle (S). $\mathrm{O}$ tratamento empregou a técnica do arco de canto associado ao aparelho extrabucal de tração alta.

\section{Métodos}

Os autores identificaram as estruturas dentoesqueléticas e do perfil tegumentar de interesse ao presente estudo e, apoiados nos postulados de McNamara Jr. ${ }^{29}$, Merrifield e $\operatorname{Cross}^{32}$, Riedel ${ }^{40,41}$, Siqueira $^{47}$, Tweed ${ }^{55,56}$, utilizaram 15 medidas ce- falométricas para as avaliações, sendo 5 lineares esqueléticas (N-Me, N-ENA, ENA-Me, S-Go e Ar-Go), 4 dentárias (6-PP, 6-ENAperp, 6-GoMe e 6-Pogperp), 3 angulares (SN.GoGn, SN.PP e PP.GoGn) e 3 proporcionais (ENA-Me/N-Me, SGo/N-Me e Ar-Go/S-Go) (Fig. 1).

\section{Metodologia empregada para a análise estatística}

Todas as radiografias foram traçadas pelo mesmo pesquisador e reavaliadas por outro profissional experiente na área, com a finalidade de se obter uma calibração dos pesquisadores.

A obtenção do erro do método realizou-se por retraçar e re-mensurar todas as telerradiografias em duas épocas distintas, obedecendo um intervalo de 1 mês entre cada traçado. Empregou-se o valor médio obtido de cada medida cefalométrica para a realização das análises estatísticas, seguindo as orientações preconizadas por Houston ${ }^{22}$ e relatadas no artigo de Valadares Neto et al. ${ }^{61}$

As grandezas cefalométricas foram analisadas descritivamente, determinando os valores mínimos, máximos, médias, e desvios-padrão para as fases inicial e final do tratamento ortodôntico empregan-

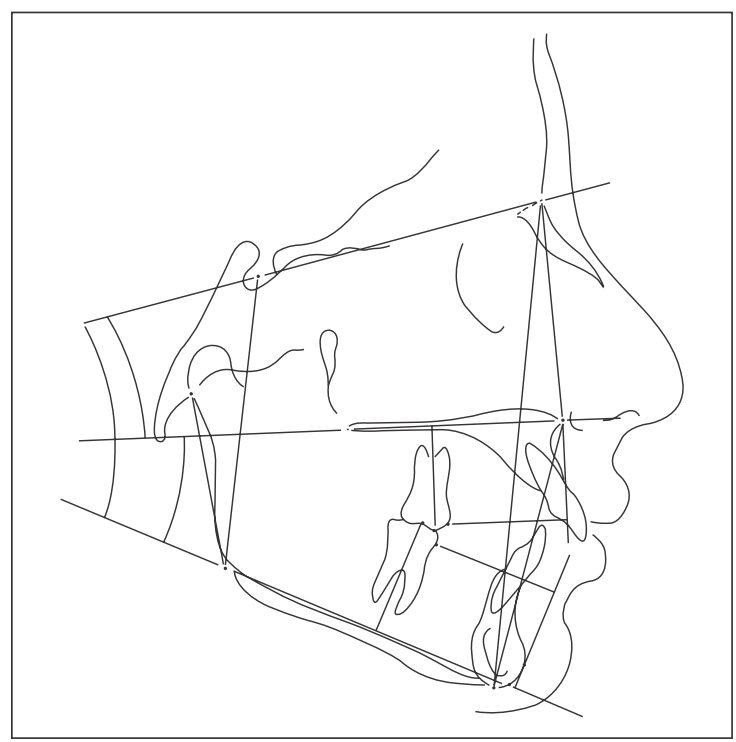

FIGURA 1 - Linhas e planos que orientaram as grandezas cefalométricas lineares e angulares. 
do-se os testes não paramétricos de Kruskal-Wallis, teste de Friedman, e análise de correlação de Pearson ( $\mathrm{r}$ ), além de avaliar as mudanças proporcionais ocorridas em cada uma das medidas ${ }^{13,24,44}$.

Além disso, foram avaliadas as mudanças proporcionais ocorridas em cada uma das medidas, ou seja, calculou-se proporcionalmente a variação da medida final em relação a medida inicial.

$$
\frac{\mathrm{T}_{1}}{\mathrm{~T}_{0}} \times 100 \%
$$

Todos os resultados foram considerados significativos para uma probabilidade de significância inferior a $5 \%(p<0,05)$, tendo portanto, pelo menos 95\% de confiança nas conclusões apresentadas.

\section{DADOS E RESULTADOS}

Não foram constatadas diferenças estatisticamente significantes entre os grupos com relação à idade no momento de exame inicial. O grupo que não foi submetido à extração dentária iniciou o tratamento com média de idade de 153,3 meses (aproximadamente 12 anos e 9 meses) variando entre os 108 e 205 meses. No grupo onde a extração dentária foi necessária, ocorreu uma variação de 109 a 196 meses com uma idade média de 142,5 meses (11 anos e 10 meses aproximadamente).

No momento de exame final, verificou-se uma diferença significante entre os grupos, com o grupo com exodontia apresentando uma idade média significantemente superior ao grupo sem exodontia, 193,3 meses (aproximadamente 16 anos e um mês), e 170,5 meses (aproximadamente 14 anos e dois meses) respectivamente.

Os valores cefalométricos estudados nesse trabalho são apresentados na tabela 1 mostrando as diferenças em milímetros entre os tempos $\mathrm{Tl}$ e T0 de cada medida avaliada, com sua significância estatística (valor "p"), para os grupos com e sem exodontias, bem como o resultado das comparações realizadas entre os grupos em relação a essas diferenças em termos proporcionais.

$\mathrm{T}_{1}$ - ao início do tratamento ortodôntico

$\mathrm{T}_{0}$ - ao final do tratamento ortodôntico

\section{DISCUSSÃO}

Existem ainda muitas controvérsias em relação aos efeitos do tratamento ortodôntico com exodontia dos primeiros pré-molares sobre a altura facial ântero-inferior, principalmente em relação a pacientes dolicofaciais. Além do padrão facial inicial, fatores como o crescimento, a mecânica ortodôntica utilizada, bem como os tipos de aparelhos empregados durante a terapia foram relacionados como capazes de influenciar na altura facial ântero-inferior (AFAI) durante o tratamento ortodôntico.

Apesar da dificuldade de controlar o crescimento, os autores optaram por pesquisar as alterações da AFAI de jovens em crescimento pois seriam eles os mais beneficiados com a possibilidade de um controle dessa dimensão para um equilíbrio facial vertical. Schudy ${ }^{45}$ afirmou que essa é a região da face que sofre as maiores variações com o crescimento e com o tratamento ortodôntico, sendo a maior responsável pelas alterações das proporções entre a altura facial ântero-inferior e total.

Enlow $^{19}$ e Ursi ${ }^{57}$ observaram o dimorfismo sexual durante o crescimento puberal em algumas medidas faciais e corporais, além da diferença de mais ou menos dois anos entre os gêneros para alcançar o pico máximo de crescimento. Bishara ${ }^{7}$ também observou dimorfismo sexual principalmente em relação aos incrementos nos tamanhos das estruturas craniofaciais, e todos sugeriram investigações separadas quanto ao gênero principalmente quando se avalia medidas lineares.

Neste trabalho avaliamos jovens dolicofaciais, pois, segundo Klapper et al. ${ }^{26}$ são esses pacientes que mais necessitam de um tratamento com controle vertical. Além disso, Nanda ${ }^{33}$, LigtheimBakker et al. ${ }^{28}$ e Sarisoy e Darendeliler ${ }^{43}$ afirmaram que o aumento da altura facial ântero-inferior durante o tratamento e crescimento é significativamente diferente entre os grupos dólico e braquifaciais.

Quanto ao tratamento utilizado, selecionamos apenas as jovens que receberam tratamentos com 
aparelhos fixos completos, empregando-se a técnica do arco de canto e força extrabucal de tração alta, pois segundo Merrifield e Cross ${ }^{33}$, Armstrong ${ }^{2}$ e Teuscher ${ }^{51}$, os aparelhos extrabucais com diversas direções de tração, produzem diferentes vetores de força e conseqüentemente influenciam de forma diferente a AFAI durante o tratamento e o crescimento. Também foram eliminadas da amostra aquelas que usaram ativadores isoladamente ou em conjunto com os aparelhos fixos, pois de acordo com Harvold e Vargervik ${ }^{21}$, os ativadores podem produzir um aumento excessivo da AFAI; e também aquelas que apresentavam Classe II, sub-divisão por não preencherem todos os requisitos de uma Classe II simétrica que define os pacientes desse trabalho.

$\mathrm{Na}$ comparação das medidas entre os grupos, observamos um aumento da altura facial anterior total, medida de $\mathrm{N}$ ao $\mathrm{Me}$, ao final do tratamento ortodôntico de $7,2 \mathrm{~mm}$ no grupo $\mathrm{S}$, valor significativamente maior do que os $4,4 \mathrm{~mm}$ observados no grupo $C$ (Tab. 1). Isso demonstra que o tratamento com exodontia dos pré-molares interferiu nessa dimensão, reduzindo a quantidade de deslocamento vertical total da face, e auxiliando na obtenção de um perfil mais equilibrado. Chua, Lim e Lubit ${ }^{12}$ observaram um maior aumento na altura facial no grupo sem exodontia especificamente na região inferior - AFAI - devido a uma rotação inferior e posterior da mandíbula. No nosso trabalho essa diferença ocorreu principalmente pelo comportamento da altura facial ântero-superior, AFAS, medida de $\mathrm{N}$ a ENA, que aumentou no grupo $\mathrm{S}$ e ficou estável no grupo $\mathrm{C}$ (Tab. 1). Esse resultado ocorreu provavelmente, como relatado anteriormente, devido ao uso mais prolon-

\begin{tabular}{|c|c|c|c|c|c|c|}
\hline \multirow{3}{*}{ Medida } & \multicolumn{4}{|c|}{$\begin{array}{l}\text { Diferença (em mm) entre os tempos } \mathrm{T}_{1} \text { e } \mathrm{T}_{0} \text { de } \\
\text { cada medida avaliada }\end{array}$} & \multicolumn{2}{|c|}{$\begin{array}{c}\text { Comparação entre os grupos em relação às } \\
\text { diferenças ocorridas }\end{array}$} \\
\hline & \multicolumn{2}{|c|}{ grupo sem exodontia } & \multicolumn{2}{|c|}{ grupo com exodontia } & \multirow{2}{*}{ Resultado comparativo } & \multirow{2}{*}{ valor de $\mathrm{p}^{* *}$} \\
\hline & diferença & valor de $\mathrm{p}^{*}$ & diferença & valor de $\mathrm{p}$ & & \\
\hline \multicolumn{7}{|l|}{ M. lineares } \\
\hline $\mathrm{N}-\mathrm{Me}$ & 7,2 & $<0,001$ & 4,4 & $<0,001$ & $\mathrm{~S}>\mathrm{C}$ & 0,011 \\
\hline N-ENA & 3,2 & $<0,001$ & 1,5 & 0,166 & $S>C$ & 0,007 \\
\hline ENA-Me & 3,5 & 0,001 & 2,3 & 0,008 & $S=C$ & 0,071 \\
\hline S-Go & 5,4 & $<0,001$ & 4,2 & $<0,001$ & $S=C$ & 0,071 \\
\hline Go-Ar & 4,6 & 0,001 & 3,3 & $<0,001$ & $S>C$ & 0,033 \\
\hline 6-PP & 2,9 & $<0,001$ & 2,0 & $<0,001$ & $S>C$ & 0,008 \\
\hline 6-ENA perp & $-0,7$ & 0,206 & $-2,4$ & $<0,001$ & $S>C$ & 0,005 \\
\hline 6-PM & 2,1 & $<0,001$ & 2,9 & $<0,001$ & $S=C$ & 0,191 \\
\hline 6-Pog perp & $-0,6$ & 0,285 & $-2,6$ & $<0,001$ & $S>C$ & 0,001 \\
\hline \multicolumn{7}{|l|}{ M. angulares } \\
\hline SN.GoGn & 0,2 & 0,366 & $-0,7$ & 0,405 & $S=C$ & 0,134 \\
\hline SN.PP & 1,4 & 0,001 & 0,3 & 0,782 & $S=C$ & 0,059 \\
\hline PP.GoGn & $-1,2$ & 0,109 & $-0,7$ & 0,166 & $S=C$ & 0,405 \\
\hline \multicolumn{7}{|l|}{ M. proporcionais } \\
\hline ENA-Me/ N-Me & $-0,6$ & 0,439 & $-0,2$ & 0,796 & $S=C$ & 0,694 \\
\hline S-Go/N-Me & 0,6 & 0,197 & 1,2 & 0,005 & $S=C$ & 0,290 \\
\hline \multirow[t]{2}{*}{ Go-Ar/ S-Go } & 2,0 & 0,005 & 1,3 & 0,001 & $S=C$ & 0,130 \\
\hline & \multicolumn{4}{|c|}{$\begin{array}{l}\text { * } 0 \text { valor p na comparação entre os momentos inicial e final de cada } \\
\text { medida refere-se ao teste Friedman }\end{array}$} & \multicolumn{2}{|c|}{$\begin{array}{c}\text { ** } 0 \text { valor p na comparação entre os grupos refere-se } \\
\text { ao teste Kruskal-Wallis }\end{array}$} \\
\hline \multicolumn{7}{|c|}{$\begin{array}{l}\text { em negrito: significância } \\
\text { S: grupo SEM exodontia } \\
\text { C: grupo COM exodontia }\end{array}$} \\
\hline
\end{tabular}


gado do extrabucal com tração alta no grupo $\mathrm{C}$ para controle de ancoragem durante a mecânica de fechamento dos espaços, que além de promover uma diferença no grau de movimento vertical dos molares superiores, promoveu também uma diferença no crescimento da maxila, mantendo-a praticamente estável no grupo $\mathrm{C}$, durante o tratamento, e permitindo um maior desenvolvimento no grupo $\mathrm{S}$.

Contrariando as afirmações efetuadas por Merrifield e $\mathrm{Cross}^{32}$ e Pearson ${ }^{36,37}$, em que a distância ENA-Me, também denominada altura facial ântero-inferior, AFAI, pode diminuir com a mesialização dos molares durante um tratamento com exodontias dos pré-molares, neste trabalho a AFAI aumentou em ambos os grupos de forma estatisticamente semelhante, não podendo ser considerada a responsável pelo maior aumento da altura facial anterior total no grupo $\mathrm{S}$, como pode ser visto na tabela 1 . Porém, o aumento médio de 3,5 $\mathrm{mm}$ no grupo $\mathrm{S}$ e de $2,3 \mathrm{~mm}$ no grupo $\mathrm{C}$, quando somados às alterações da AFAS, produziram um aumento significativamente maior da altura facial anterior total (AFAT) no grupo $\mathrm{S}$ de $2,8 \mathrm{~mm}$, já relatado anteriormente.

A tabela 1 e a figura 5 mostram que a distância vertical 6-PP aumentou nos dois grupos mas foi estatisticamente menor no grupo $\mathrm{C}$, provavelmente devido ao maior tempo de uso do extrabucal neste grupo durante a retração dos dentes anteriores, concordando com as observações de Ricketts $^{39}$, que afirmou que os dentes alteram as suas posições dramaticamente com o uso de extrabucais, mesmo quando usados de 12 a 14 horas por dia.

No entanto, esse mesmo sistema de ancoragem não foi capaz de controlar totalmente a posição ântero-posterior dos molares superiores. Neste trabalho não se constatou uma distalização real do molares, pelo contrário, mesmo com o uso da ancoragem extrabucal, obteve-se um deslocamento anterior desses dentes em ambos os grupos, porém com muito mais intensidade no grupo com exodontias onde ocorreu uma movimentação estatis- ticamente significante de 2,4 $\mathrm{mm}$, contra apenas $0,7 \mathrm{~mm}$ no grupo $\mathrm{S}$, sem significância estatística, como pode ser observado na tabela 1 e na figura 5. Esses resultados não suportam os achados de Merrifield e $\mathrm{Cross}^{32}$ e de Baumrind et al. ${ }^{3}$, onde eles observaram um movimento distal dos molares superiores provocando uma rotação posterior da mandíbula com conseqüente aumento da altura facial ântero-inferior.

Em relação aos primeiros molares inferiores constatou-se que os dois grupos apresentaram um aumento vertical estatisticamente significante em relação ao plano mandibular (6-GoGn) entre os tempos $T_{0}$ e $T_{1}$, porém sem diferença estatística entre os grupos, ou seja, o deslocamento dos molares inferiores ocorreu de forma semelhante em ambos os grupos. No movimento horizontal, a situação foi similar ao molar superior, com uma leve mesialização sem significado estatístico no grupo $\mathrm{S}$ e uma mesialização significante no grupo $\mathrm{C}$. $\mathrm{Na}$ comparação entre os grupos, constatou-se uma diferença estatisticamente significante, onde a distância 6Pogperp tornou-se estatisticamente menor no grupo $\mathrm{C}$ ao final do tratamento (Tab. 1 e Fig. 5). Pearson ${ }^{36}$ relatou a necessidade de controlar o deslocamento oclusal dos molares, inclusive dos inferiores para obter uma diminuição do ângulo do plano mandibular, e utilizou no seu trabalho a mentoneira vertical para esse fim, obtendo resultados significantes na ordem de $3,9^{\circ}$. Em 1986 esse mesmo autor ${ }^{37}$ observou que os jovens que não colaboraram em relação ao uso das mentoneiras verticais durante o tratamento ortodôntico, tiveram um aumento da AFAI semelhante entre os grupos com e sem exodontias dos pré-molares, na ordem de 6,2 $\mathrm{mm}$ e $6,5 \mathrm{~mm}$ respectivamente, enquanto os jovens colaboradores apresentaram um aumento da AFAI de apenas 2,6 $\mathrm{mm}$ no grupo com exodontias e de $6,0 \mathrm{~mm}$ no grupo sem exodontias.

É interessante salientar que no grupo sem exodontias (grupo S) somente as dimensões li- 
neares 6-ENAperp. e 6-Pog.perp. não apresentaram diferenças estatisticamente significantes entre os valores iniciais e finais. A manutenção de valores que medem posições dentárias indica que esses elementos conservaram suas posições independente do crescimento ou tratamento ortodôntico. Geralmente os tratamentos que não necessitam de exodontias apresentam apinhamentos leves ou moderados onde os espaços para o alinhamento são conquistados por meio do arredondamento do arco, leves expansões transversais, nivelamento da curva de spee e projeções anteriores, além da distalização dos molares, essa última não observada nesse trabalho, permitindo a manutenção da posição ântero-posterior dos molares superiores e inferiores em relação às suas bases ósseas. De acordo com Creekmo$\mathrm{re}^{14}$, nos casos sem exodontia o movimento distal dos molares não é suficiente para corrigir a Classe II, e a correção ocorre pelo somatório do movimento dentário, crescimento mandibular e inibição do crescimento maxilar. Harris, Dyer e Vaden $^{20}$, avaliando uma amostra de adolescentes com má oclusão de Classe II, divisão 1, do gênero feminino, tratadas com aparelho fixo e tração extrabucal alta, observaram que $70 \%$ da correção molar ocorreu devido ao crescimento e somente 30\% aos movimentos dentários. Para Chua, Lim e Lubit $^{12}$, a correção da Classe II também ocorreria pelo crescimento e rotação mandibular.

Nas medidas angulares, os ângulos SN.GoGn e o PP.GoGn permaneceram estatisticamente inalterados do início ao fim dos tratamentos em ambos os grupos (Tab. 1). Somente o ângulo SN.PP, no grupo S, apresentou uma alteração estatisticamente significante, com um aumento médio de $1,4^{\circ}$. Contudo, essa alteração não foi suficiente para produzir uma diferença estatística entre os grupos. Esses resultados indicam que as alterações verticais ocorridas na altura facial anterior foram proporcionalmente semelhantes às alterações da altura facial posterior. Cusimano, McLaughlin e Zernik ${ }^{15}$ obtiveram resultado semelhante em relação ao ângulo do plano mandibular, medido em SN.GoGn, que se manteve inalterado durante o tratamento de jovens portadores de mordida aberta esquelética que se submeteram à exodontia dos quatro primeiros pré-molares. Para os autores, o movimento vertical dos molares associado ao crescimento vertical das estruturas craniofaciais impediram a diminuição do ângulo do plano mandibular que poderia ocorrer devido ao movimento mesial dos mesmos, mantendo-o praticamente inalterado. Melsen ${ }^{31}$, citada por Dyer, Harris e Vaden ${ }^{18}$ também afirmou que o crescimento condilar e o desenvolvimento alveolar vertical permitem alguma extrusão durante tratamento ortodôntico nos adolescentes sem que ocorra rotação mandibular. Contrariando esses achados, Chua, Lim e Lubit $^{12}$ observaram uma rotação posterior e inferior da mandíbula com conseqüente aumento da AFAI em jovens com má oclusão de Classe I e Classe II que se submeteram ao tratamento sem exodontias. Por outro lado, os tratamentos realizados com exodontia dos pré-molares não apresentaram qualquer relação das exodontias com as alterações da AFAI.

\section{CONCLUSÕES}

Considerando-se as características da amostra utilizada, a metodologia empregada e baseando-se nos resultados obtidos no decorrer dessa investigação, concluímos que:

1) A exodontia dos primeiros pré-molares não foi capaz de diminuir a AFAI em jovens dolicofaciais do gênero feminino em crescimento. A extrusão dos molares superiores e inferiores durante a mesialização, a erupção e o crescimento dos processos alveolares, bem como o crescimento da maxila para frente e para baixo não permitiram que ocorresse uma diferença nas alterações da AFAI (ENA-Me) entre os grupos, que aumentou de forma estatisticamente semelhante em ambos.

2) Ocorreu um aumento da AFAT (N-Me) em 
ambos os grupos, porém com uma intensidade significativamente maior no grupo sem exodontias, devido ao maior aumento da AFAS (N-ENA) neste grupo, indicando que o crescimento da face média possui um papel preponderante na determinação da dimensão vertical e que o controle do crescimento vertical maxilar por meio de aparelhos ortopédicos extrabucais pode inibir esse crescimento durante o tratamento ortodôntico. Neste trabalho o uso do aparelho extrabucal com tração alta foi importante para diminuir a intensidade de crescimento vertical da maxila, tornando a Altura Facial Anterior Total (N-Me) mais equilibrada.

3) Não ocorreu o movimento distal dos molares superiores durante o tratamento nas jovens com Classe II, divisão 1, que utilizaram o aparelho extrabucal de tração alta e que não se submeteram à exodontia dos primeiros pré-molares. Os dois grupos apresentaram movimentações anteriores dos molares, com maior intensidade no grupo com exodontias, fato que não causou diferença estatisticamente significante nas alterações da AFAI entre os grupos quando analisado isoladamente, mas quando somado às alterações ocorridas na AFAS produziu diferença estatisticamente significante da AFAT entre os grupos.

4) Observou-se que a manutenção dos valores angulares durante o tratamento foi devida ao crescimento vertical posterior (S-Go) que ocorreu na mesma proporção do crescimento da região anterior da face (N-Me) em ambos os grupos.

5) Observou-se que o controle da extrusão dos molares é importante para se obter um controle efetivo da altura facial anterior nos jovens dolicofaciais em crescimento submetidos ao tratamento ortodôntico.

\title{
The effect of first premolars extractions on the lower anterior facial height.
}

\begin{abstract}
Premolar extractions are often utilized as part of orthodontic treatment to solve a wide range of problems. However, its use to control vertical dimension is still controversial. This retrospective study investigated the lateral cephalometric measurements of 30 dolichocephalic girls, with Class II division 1 malocclusion. These patients were treated with edgewise appliances and high traction headgear. From the whole group 15 had four first bicuspids extractions and 15 had no extractions. The mean age was 12.3 years, ranging from 9 to 17 years. The cephalometric measurements N-Me, N-ANS, ANS-Me, S-Go, Ar-Go, 6-PP, 6-ANSperp, 6-GoGn, 6-Pogperp, SN.GoGn, SN.PP, PP.GoGn, ANS-Me/N-Me, S-Go/N-Me, and Go-Ar/S-Go were used in the study. The study revealed that: 1) the extraction of the first premolar associated with extrusion of the first molars and growth did not cause any difference in the lower anterior facial height between the two groups; 2) both upper and lower first molars moved mesially in the extraction group; 3) the increase in the lower anterior facial height was similar for both groups; 4) the total anterior facial height was larger in the non extraction group due to a higher increase in the upper anterior facial height; and 5)- the angular measurements did not change significantly in both groups during treatment, most likely because growth between the posterior and the anterior vertical dimension were balanced.
\end{abstract}

Key words: Anterior facial height. Extractions. Premolars. 


\section{REFERÊNCIAS}

1. APOLINÁRIO, A. C. E.; JARDIM, R. V. Alterações cefalométricas da face inferior após a extração do pré-molares. Rev Goiana de Ortodon, Goiânia, v. 6, n.1, 15-23, mar./ago. 2001.

2. ARMSTRONG, M. M. Controlling the magnitude, direction, and duration of extraoral force. Am J Orthod, St. Louis, v. 59, no.3, 217-243, Mar. 1971.

3. BAUMRIND, S. et al. Mandibular plane changes during maxillary retraction. Part 2. Am J Orthod, St. Louis, v.74, no. 6, p. 603620, Dec. 1978

4. BAUMRIND, S. et al. The decision to extract: Part II. Analysis of clinicians' stated reasons for extraction. Am J Orthod Dentofacial Orthop, St. Louis, v.109, no. 4, p. 393-402, Apr. 1996.

5. BISHARA S. E.; PETERSON, L. C.; BISHARA, E. C. Changes in facial dimensions and relationships between the ages of 5 and 25 years. Am J Orthod, St. Louis, v. 85, no. 3, p. 238-352, Mar. 1984.

6. BISHARA, S. E.; ORTHO, D.; CUMMINS D. M.; JAKOBSEN, J. R. The morphologic basis for the extraction decision in class II, division 1 malocclusions: a comparative study. Am J Orthod Dentofacial Orthop, St. Louis, v.107, no. 2, p.129-135, Feb.1995

7. BISHARA, S. E.; ORTHO D : JAKOBSEN, J. R.; ANGELAKIS, D. Posttreatment changes in male and female patients: a comparative study. Am J Orthod Dentofacial Orthop, St. Louis, v. 110 no. 6, p. 624-629, Dec.1996.

8. BISHARA, S.E Mandibular changes in persons with untreated and treated class II division 1 malocclusion. Am J Orthod Dentofacial Orthop, St. Louis, v. 113, no. 6, p. 661-673, June 1998.

9. BJÖRK, A. Prediction of mandibular growth rotation. Am J Orthod, St. Louis, v. 55, no. 6, p. 585-599, June 1969.

10. BJÖRK, A.; SKIELLER, V. Growth of the maxilla in three dimensions as revealed radiographically by the implant method. Br J Orthod, London, v. 4, no. 2, p. 53-64, Mar. 1977.

11. BJÖRK, A.; SKIELLER, V. Normal and abnormal growth of the mandible: a syntesis of longitudinal cephalometric implant studies over a period of 25 years. Eur J Orthod, London, v. 5, no.1, p. 1-46, Feb. 1983.

12. CHUA, A.; LIM, J. Y. S.; LUBIT, E. C. The effects of extraction versus nonextraction orthodontic treatment on the growth of the lower anterior face height. Am J Orthod Dentofacial Orthop, St. Louis, v. 104, no. 4, p. 361-368, Oct. 1993.

13. CONOVER, W. J. Practical nonparametric statistics. New York: John Wiley, 1980.

14. CREEKMORE, T. D. Inhibition or stimulation of the vertical growth of the facial complex, its significance to treatment. Angle Orthod, Appleton, v. 37, no. 4, p. 285-297, Oct. 1967

15. CUSIMANO, C.: MCLAUGHLIN, R. P. ZERNIK, J. H. Effects of first bicuspid extractions on facial height-angle cases. J Clin Orthod, Boulder, v. 27, no.11, p. 594-598, Nov. 1993

16. DERMAUT, L. R.; O'REILLY, M. I. T. Changes in anterior facial heigth in girls during puberty. Angle Orthod, Appleton, v. 48, no. 2, p.163-171, Apr. 1978

17. DEWEL, B. F. The case-dewey-cryer extraction debate: a commentary. Am J Orthod, St. Louis, v. 50, no.11, p. 862-865, Nov. 1964.

18. DYER,G. S.; HARRIS, E. F.; VADEN, J. L. Age effects on orthodontic treatment: adolescents contrasted with adults. Am J Orthod Dentofacial Orthop, St. Louis, v.100, no. 6, p. 523-530, Dec. 1991.

19. ENLOW, Donald H. Crescimento facial. 3. ed. Trad. Silvia Fuerte Bakor. São Paulo: Artes Médicas, 1993.

20. HARRIS, E. F.; DYER, G. S.; VADEN, J. L. Age effects on orthodontic treatment: skeletodental assessments from the Johnston analysis. Am J Orthod Dentofacial Orthop, St. Louis, v.100 no. 6, p. 530-536, Dec. 1991

21. HARVOLD, E. P.; VARGERVIK, K. Morphogenetic response to activator treatment. Am J Orthod, St. Louis, v. 60, no. 5, p. 478490, Nov. 1971

22. HOUSTON, W. J. B. The analysis of erros in orthodontic measurements. Am J Orthod, St. Louis, v. 83, no. 5, p. 382-390, May 1983.

23. ISAACSON, J. R. et al. Extreme variation in vertical facial growth and associated variation in skeletal and dental relations. Angle Orthod, Appleton, v. 41, no. 3, p. 219-229, July 1971
24. JOHNSON, R.; BHATTACHARYYA, G. Statistics principles and Methods. New York: John Wiley, 1986.

25. KARLSEN, A. T. Association between facial height development and mandibular growth rotation in low and high MP-SN angle faces: a longitudinal study. Angle Orthod, Appleton, v. 67, no. 2, p.103-110, 1997

26. KLAPPER, L. et al. The influence of extraction and nonextraction orthodontic treatment on brachyfacial and dolichofacia patterns. Am J Orthod Dentofacial Orthop, St. Louis, v. 101, no. 5, p. 425-430, May 1992.

27. KOCADERELI, I. The effect of first premolar extraction on vertical dimension. Am J Orthod Dentofacial Orthop, St. Louis, v. 116, no.1, p. 41-45, July 1999.

28. LIGTHEIM-BAKKER, A. S. W. M. R.; WATTEL, E.; ULJEE, I.H.; PRAHL-ANDERSEN, B. Vertical growth of the anterior face: a new approach. Am J Orthod Dentofacial Orthop, St. Louis, v.101, no. 6, p. 509-513, June 1992

29. McNAMARA Jr., J. A. A method of cephalometric evaluation. Am J Orthod, St. Louis, v. 86, no. 6, p. 449-469, Dec. 1984.

30. McLAUGHLIN, R. P.; BENNETT, J. C. The extraction-nonextraction dilema as it relates to TMD. Angle Orthod, Appleton, no. 3, p.175-186, Sept. 1995.

31. DYER, G. S.; HARRIS, E. F.; VADEN, J. L. Age Effects on orthodontic treatment: Adolescents contrasted with adults. Am J Orthod Dentofacial Orthop, St. Louis, v. 100, no. 6, p. 523-530, Dec. 1991.

32. MERRIFIELD, L. L.; CROSS J. J. Direcional forces. Am J Orthod, St. Louis, v. 57, no. 5, p. 435-464, May 1970.

33. NANDA, S. K. Patterns of vertical growth in the face. Am J Orthod Dentofacial Orthop, St. Louis, v. 93, no. 2, p. 103-116, Feb. 1988.

34. ORTIAL, J. P. Vertical dimension and therapeutic choices. Am J Orthod Dentofacial Orthop, St. Louis, v. 108, no. 4, p. 432 441, Oct. 1995

35. PAQUETTE D. E.; BEATTIE J. R.; JOHNSTON, L. E. A long-term comparison of nonextraction and premolar extraction edgewise therapy in "borderline" Class II patientes. Am J Orthod Dentofacial Orthop, St. Louis, v.102, no.1, p.1-14, July 1992

36. PEARSON, L. E. Vertical control in treatment of patients having backward-rotational growth tendencies. Angle Orthod, Appleton, v. 48, no. 2, p. 132-140, Apr. 1978

37. PEARSON, L. E. Vertical control in fully-banded Orthodontic Treatment. Angle Orthod, Appleton, v. 56, no. 2, p. 205-224, June 1986.

38. PROFFIT, W. R.; PHILLIPS, C.; DOUVARTZIDIS, N. A comparison of outcomes of orthodontics and surgical-orthodontic treatment of class II malocclusion in adults. Am J Orthod Dentofacial Orthop, St. Louis, v.101, no. 6, p. 556-565, June 1992.

39. RICKETTS, R. M. The influence of orthodontic treatment on facial growth and development. Angle Orthod, Appleton, v. 30, no. 3, p.103-133, July 1960.

40. RIEDEL, R. A. The relation of maxillary structures to cranium in maloccusion and normal occlusion. Angle Orthod, Appleton, v. 22, no. 3, p. 142-145, July 1952.

41. RIEDEL, R. A. An analysis of dentofacial relationships. Am J Orthod, St. Louis, v. 43, no. 32, p.103-119, Feb. 1957.

42. ROTHSTEIN, T.: YOON-TARLIE, C. Dental and facial characteristics and growth of males and females with class II, division 1 malocclusion between the ages of 10 an 14 (revisited) - Part I: characteristics of size, form and position. Am J Orthod Dentofacial Orthop, St. Louis, v.117, no. 3, p. 320-332, Mar. 2000.

43. SARISOY, L.T.; DARENDELILER, N. The influence of extraction orthodontic treatment on craniofacial structures: Evaluation according two different factors. Am J Orthod Dentofacial Orthop, St. Louis, v.115, no. 5, p. 508-514, May 1999.

44. USER'S Guide: statistics version 5. [S. I.]: SAS Institute, 1985.

45. SCHUDY, F. F. Vertical growth versus anteroposterior growth as related to function and treatment. Angle Orthod, Appleton, v. 34, no. 2, p. 75-93, Apr. 1964. 
46. SINGH, I. J.: SAVARA, B. S. Norms of size and annual increments of seven anatomical measures of maxillae in girls from three to sixteen years of age. Angle Orthod, Appleton, v. 36, no. 4 p. 312-324, Oct. 1966.

47. SIQUEIRA, V. C. V. Avaliação da recidiva da sobressaliência, em pacientes com Classe II, $1^{\text {a }}$ divisão, submetidos a extrações dos quatro primeiros pré-molares: estudo cefalométrico longitudinal, realizado ao início, final e 5 anos após o tratamento ortodôntico 1996. $322 \mathrm{f}$. Tese (Doutorado em Ortodontia) - Faculdade de Odontologia de Bauru, Universidade de São Paulo, Bauru, 1966

48. STAGGERS, J. A. A comparison of results of second molar and first premolar extraction treatment. Am J Orthod Dentofacial Orthop, St. Louis, v. 98, no. 5, p. 430-436, Nov. 1990.

49. STAGGERS, J. A. Vertical changes following first premolar extractions. Am J Orthod Dentofacial Orthop, St. Louis, v.105 no. 1, p.19-24, Jan. 1994.

50. STEINER, C. C. Cephalometric for you and me. Am J Orthod St. Louis, v. 39, no.10, p.729-755, Oct. 1953.

51. TEUSCHER, U. An appraisal of growth and reaction to extraoral anchorage. Simulation of orthodontic-orthopedic results. Am J Orthod, St. Louis, v. 89, no. 2, p. 113-121, Feb. 1986.

52. TOFANI, M. I. Mandibular growth at puberty. Am J Orthod, St. Louis, v. 62, no. 2, p.176-195, Aug. 1972

53. TULLOCH, J.F. C.: MEDLAND, W. TUNCAY, O. A. Methods used to evaluate growth modification in class II malocclusion. Am J Orthod Dentofacial Orthop, St. Louis, v. 98, no. 4 p. $340-347$, Oct. 1990
54. TUNCAY, O. A. TULLOCH, J. F.C. Apparatus criticus: methods used to evaluate growth modification in class II malocclusion. Am J Orthod Dentofacial Orthop, St. Louis, v.102, no. 6 p. 531-536, Dec. 1992

55. TWEED. C. H. Evolutionary trends in orthodontics, past, present and future. Am J Orthod, St. Louis, v. 39, no. 2 p. 81-108, Feb. 1953.

56. TWEED, C. H. The Frankfourt-mandibular incisor plane Angle (FIMA) in orthodontic diagnosis, treatment, planing and prognosis. Angle Orthod, Appleton, v. 24, no. 3, p.121-169, July 1954.

57. URSI, W. J. S. Crescimento e alterações nas relações mandibulares dos 6 aos 18 anos de idade. Ortodontia, São Paulo, v. 29 n. 1, p. 4-12, jan./abr. 1996

58. VADEN J.L. Sequencial directional forces treatment: Two class II case reports. Am J Orthod Dentofacial Orthop, St. Louis, v. 99 no. 4, p. 491-504, June 1991

59. VADEN, L. J.; KISER, H. E. Straight talk about extraction and nonextraction: A differential diagnostic decision. Am J Orthod Dentofacial Orthop, St. Louis, v. 109, no. 4, p. 445-452, Apr. 1996.

60. VADEN, J. L. Nonsurgical treatment of the patient with vertical discrepancy. Am J Orthod Dentofacial Orthop, St. Louis, v. 113 , no. 5 , p. 567-582, May 1998

61. VALADARES NETO, J.: DOMINGUES, M. H. M. S.; CAPELLOZZA FILHO, L. Pesquisa em ortodontia: bases para a produção e a análise. R Dental Press Ortodon Ortop Facial, Maringá, v. 5, n. 4, p. 89-105, jul./ago. 2000.

\author{
Endereço para correspondência \\ Vania C. V. Siqueira \\ Rua José Corder 87 \\ Jardim Modelo \\ CEP: $13400-010$ \\ Piracicaba - SP \\ E-mail: siqueira@fop.unicamp.br
}

